\title{
Exploration and Practice of Japanese Practical Courses Against the Background of Mixed Education Reform*
}

\author{
Yao Fu \\ Department of Japanese \\ School of Foreign Languages \\ Dalian Neusoft University of Information \\ Dalian, China 116023
}

\begin{abstract}
Japanese practice courses play an important role in the curriculum system, so it has become one of the topics of Japanese teaching research. In recent years, the reform of mixed education has been continuously promoted. This paper focuses on the Japanese practical courses and analyzes its exploration and practice in the context of mixed education reform. Through the exploration of its teaching content, teaching implementation methods and assessment methods on the road of mixed reform, the paper analyzes the achievements and inadequacies of its teaching reform, so as to provide some reference for the teaching reform of practical courses.
\end{abstract}

Keywords-mixed education reform; practical course; course content; assessment method

\section{INTRODUCTION}

The concept of mixed learning has different definitions and different opinions. Generally speaking, under the rapid development of information technology, in order to further mobilize students' enthusiasm for learning and optimize learning resources, a comprehensive and diverse learning model consisting of emerging learning modes such as MOOC, micro-course, online course, and flip classroom is used.

The hybrid teaching mode is a new teaching mode that combines the traditional teaching with the Internet teaching. It focuses on the cooperation between online and offline, emphasizing the teaching philosophy of taking students as the main body and teachers as the leading. With the continuous deepening of educational informationization and the rise of MOOC and micro-courses, hybrid teaching has a richer connotation, and it also further promotes the reform and exploration of the existing teaching system in colleges and universities. How to make use of the developed network to combine online education with offline education has become one of the topics that colleges and universities need to solve. Under the craze of mixed education reform in

*This thesis is the result of the phased research of the "Diversified Foreign Language Teaching Evaluation System under the Hybrid

Education Model" (JRW2019001) of the 2019 Scientific Research Fund Project of the Liaoning Provincial Department of Education. colleges and universities across the country, how to give full play to the original advantages and explore a science curriculum that is more in line with the needs of the times and achieve the goal of training will become the top priority of all universities.

\section{EXPLORATION AND PRACTICE OF JAPANESE PRACTICAL COURSES}

\section{A. The Status and Role of Practical Courses}

In recent years, with the expansion of the demand for applied talents in society, how to cultivate applicationoriented talents that meet the needs of society has become one of the goals of teaching reform in major universities. There are many factors that determine the effectiveness of the teaching reform, and the construction of the curriculum system can play a pivotal role. The curriculum system is divided into theoretical courses and practical courses. The theoretical course can teach the theoretical knowledge that should be possessed in the practical stage; the practical course can complete the conversion of students' theoretical knowledge to practice. The rationality of the practical curriculum will determine whether it can complete the seamless connection of students from the campus to society. Therefore, the practical curriculum will play an important role in the cultivation of applied talents.

The course objectives of the Japanese professional practice course can be summarized as improving the ability to express business Japanese and strengthening the understanding and application of business etiquette. After studying a period of the systematic theoretical knowledge, students have mastered a certain amount of Japanese vocabulary and grammar. Through the teaching links and teaching content of the practical curriculum, the students' theoretical knowledge can be fully exercised, so as to achieve the teaching purpose of the students truly mastering a language. 


\section{B. Analysis of the Status Quo of Japanese Practical Courses}

The Japanese language courses belong to the language courses. The language practice courses are mainly based on the output principle, that is, the performance of the students' listening, speaking, reading, writing and translating skills in the simulated context or the real scene. As a Japanese practice course, the "Speech, Listening and Speaking" course was set up in the training of "listening and speaking", and the "Flat Reading" and "Writing" courses were set up in the training of "reading and writing". Such courses are more traditional practice courses. In recent years, with the emphasis on practical courses in colleges and universities, practical courses have been set up to meet the students' knowledge level and structure. For example, "Business Japanese Workplace Practice - Translation Direction" "Business Japanese Workplace Practice - Tourism Direction". This type of curriculum is directly related to the work content that the students will be engaged in. It can simulate the actual work content, and also temper the students' actual language ability and strengthen students' understanding of Japanese culture and business etiquette. In addition, in order to improve the application ability of students, it also provides practical courses such as "Japanese office" and other pure operation types.

On the other hand, in order to cooperate with the practice courses, many colleges and universities have set up theoretical semester and practical semester on the basis of the traditional school year. That is, the courses offered in the theoretical semester focus on the acquisition of linguistic knowledge, and the courses in the practical semester focus on cultivating the language skills and operational ability. For example, according to the students' different Japanese proficiency, in the four academic years of the university, each academic year is equipped with practical courses corresponding to their Japanese level in order to cultivate students' business Japanese language ability. The Japanese foundation of the freshman year is still in a weak stage, so the practical course is set to practice the "Business Japanese Scene Training" for a single scene; the Japanese foundation of the sophomore year has a certain foundation, and students can handle medium and long sentences, so the curriculum of the semester is practiced for the "Business Japanese Process Practice" with complicated conversation content; the junior year has basically completed the teaching content of the university stage. Therefore, the practice semester is based on the "Business Japanese Comprehensive Training" centered on the workplace. It can be seen that the setting of practical courses is interlocking and progressive, which fully achieves the purpose of cultivating students' language application ability

\section{EXPLORING THE REFORM OF MIXED EDUCATION IN JAPANESE PRACTICAL COURSES}

\section{A. Teaching Implementation Content and Implementation Method}

Under the guidance of the teaching concept of mixed education reform, practical courses start from the perspective of students and teachers, and the teaching implementation content and implementation methods are designed from three dimensions: pre-class, in-class and after-class.

Pre-class: Teachers use the project teaching platform to arrange online micro-video learning tasks. At the same time, they check the student's online learning situation and imagine the difficulties in the video, in order to prepare for the class and discuss with the students. At the same time, they let students preview the introduction part of the textbook in order to learn better.

In-class: the teacher displays the micro-videos arranged after the class, and provides concentrated answers to the students' questions; teachers test the students' pre-school learning effects through the micro-course supporting exercises; they comment on the students' online learning and answers; they guide the students to set and publish the scenes related to the classroom content with the project team as a unit and organize students to publish and evaluate, and give feedback on the evaluation results. Students search information online in groups, and combine the learned knowledge to complete the preparation of the content in the class; students display the project in groups, and complete mutual evaluation within the group and among groups.

After class: the teacher views the students' online learning and problems in the class, in order to prepare for the common problems in the class; for the assignments submitted by the students, a set of documents is taken as an example for evaluation, in order to prepare the class comments; teachers revise the documents of unit projects submitted by students to prepare for guiding the common problems in class. Students complete the relevant microcurriculum study and complete 5 online test questions; the group submits the published video and PPT online in groups; they need to create the manuscripts of making and receiving a phone call in groups and submit it online.

\section{B. Assessment Method}

Since the teaching objectives of the practical courses mainly cultivate students' practical ability such as listening and speaking, its assessment methods are mainly in the form of oral examinations and small papers. This kind of examination method has no objective evaluation criteria, and mainly relies on the scoring standard for subjective evaluation. The subject of the evaluation is generally the instructor. For the integrity of the assessment, the assessment method will be divided into the final assessment of the formation performance assessment of the usual performance and the study effect at the end of the semester. Because of the focus of the practical courses, the proportion of formative assessment and final assessment is 6:4. This proportion of performance helps to encourage students to learn and develop their learning habits.

Under the guidance of the mixed education reform thinking, the practical courses have made bold attempts in the teaching methods and other aspects. In order to ensure the teaching effect, the assessment methods should be reformed on the basis of the original examination methods. Due to the increase of online and offline teaching resources, 
[2] Zhao Hui.Exploration of Information Teaching of Business Japanese Listening and Speaking in Higher Vocational Colleges - B ased on the Resource Use Perspective of Blue Moyun Class [J]. Journal of Hubei Open Vocational College,2019,32(08):152-153.

the form of assessment should not only be limited to oral testing and small papers, but also increase the assessment of video works. That is to complete a certain stage or final assessment in the form of submitting a video work. On the one hand, this kind of assessment method can integrate the learning effects of online micro-courses and teaching videos into the works, and on the other hand, it allows students to expand the practice places beyond the classroom. It increased the fun of learning and achieved the diversity of assessments. The evaluation subject should also shift from teacher evaluation to teacher-led evaluation of student participation evaluation. In the past, the evaluation was mainly for teachers, so the participation of students was low, which made students reluctant to participate in the works of others. This is not conducive to students learning from others. Due to the advancement of the hybrid education reform, the evaluated works can be put on the online platform for teachers and students to watch the evaluation many times, which is conducive to the exchange progress among the students and the fairness and reasonableness of the test results.

\section{ISSUES TO BE RESOLVED}

In the exploration and practice of curriculum reform, the Japanese practical courses have achieved certain results in the design of teaching content and assessment methods. But there are still problems in many aspects. For example, in the management of teaching organizations, the supervision and the guidance for students in-class and after-class can be completed well. However, due to the large number of classes, the monitoring of the completion of students' offline operations has yet to be improved. In addition, in the process of publishing the course project, the participation of students waiting for publication is not high, and the monitoring methods of teachers still need to be further explored. In terms of teaching resources, most practical courses are mostly theoretical materials, and there are few real cases. In addition, according to the feedback from students, students' understanding of the original Japanese video in the teaching process is also difficult. Based on the above questions, rethinking the content setting and organization form of the course has become a major issue for future reform.

\section{CONCLUSION}

In summary, the hybrid education reform has achieved initial results in the practice of Japanese-language teaching courses. The practical courses are attached to various informatization resources such as micro-courses, MO0C, flipping classrooms and other online open courses. They are integrated with traditional classroom teaching, which can greatly enhance students' enthusiasm and creativity, and also make full use of the Internet to enhance students' foreign language ability.

\section{REFERENCES}

[1] Yan Li,Zhang Ning.Exploration of College English Mixed Teaching Reform under the Vision of "Internet" - Comment on "Inquiry into College English Mixed Teaching" [J]. News Enthusiast,2019(07):98.
[3] Liu Xiaohang.The Application of Achievement-oriented Education Concept in Business Japanese Practice Teaching [J]. Journal of Nanchang College of Education,2018,33(03):94-97.

[4] Zhou Guangyu.Analysis on the Multi-dimensional Stereoscopic Practice Teaching System of Business Japanese Majors [J]. Journal of Jiamusi Vocational College,2018(07):379.

[5] Lu Lijun.The Application of "Construction Grammar Theory" in Japanese Practical Teaching under the School-Enterprise Cooperation Mode [J]. Journal of Dalian University,2018,39(05):117-121. 